\title{
TGF- $\beta 1$ serum concentrations and receptor expressions in the lens capsular of dogs with diabetes mellitus
}

\author{
Stephan Neumann ${ }^{1, *}$, Jens Linek ${ }^{2}$, Gerhard Loesenbeck ${ }^{3}$, Julia Schüttler ${ }^{1}$ and Sonja Gaedke ${ }^{1}$ \\ ${ }^{1}$ Institute of Veterinary Medicine, University of Goettingen, Burckhardtweg 2, D-37077 Goettingen, Germany \\ ${ }^{2}$ Veterinary specialists, Hamburg, Germany \\ ${ }^{3}$ Laboklin GmbH\&CO.KG, Bad Kissingen, Germany
}

\begin{abstract}
Tissue fibrosis as complication of diabetes mellitus is known in humans. Because TGF- $\beta 1$ induces fibrosis and is elevated in humans suffering from diabetes mellitus we measured this growth factor in serum of dogs with diabetes mellitus and compared it with healthy dogs and those with fibrotic diseases. Further we measured the expression of TGF- $\beta 1$ receptor on lens capsule to investigate possible association between diabetes mellitus and cataract associated alterations. TGF- $\beta 1$ was measured in serum of 12 dogs with diabetes mellitus, 20 healthy controls and 12 dogs with fibrotic diseases. Dogs with diabetes mellitus and fibrotic diseases have significantly increased TGF- $\beta 1$ serum concentrations compared to healthy controls. Some dogs with diabetes mellitus showed increased expression of TGF$\beta 1$ receptor in lens capsule. Based on our observations we can conclude that TGF- $\beta 1$ elevation in dogs with diabetes mellitus may induces complications of the disease and may participates on lens alteration.
\end{abstract}

Keywords: Cataracts, Diabetes mellitus, Dogs, TGF- $\beta 1$.

\section{Introduction}

Diabetes mellitus is one important endocrine disease in humans as well as in dogs. Clinical complications of diabetes mellitus influence functions in different organs and can induce on this way beside others neuropathy, retinopathy and glomerulopathy (Gangwani et al. 2016; Juster-Switlyk and Smith, 2016; Leung et al., 2016). All these diseases are described as microvascular complications of diabetes mellitus (Gilbert, 2013). The underlying mechanism was firstly described in the sixties and includes fibrosis of extracellular matrix (Siperstein et al., 1968; Tsilibary, 2003). Compared to humans dogs with hyperglycemia also develop microvascular alterations (Gardiner et al., 1994). Because fibrosis is part of the pathogenesis of diabetic complications we hypothesized that growth factors, which induce tissue fibrosis should play a role in the pathogenesis.

One growth factor which induces tissue fibrosis is Transforming growth factor beta 1 (TGF- $\beta 1$ ). TGF- $\beta 1$ is a pleiotropic cytokine that belongs to the TGFsuperfamily. TGF- $\beta 1$ is secreted by a large number of cells. This cytokine contributes to the proliferation and differentiation of cells, embryonic development, wound healing and angiogenesis (Sporn et al., 1990; Lawrence, 1996; Alevizopoulos and Mermod, 1997). Additionally, it is influenced by or influences the pathogenesis of many diseases (Blobe et al., 2000). Data from human medicine show variable blood concentrations, compared to healthy controls, in patients with cancer, immunological, fibrotic or sclerotic diseases (Colitz et al., 2000; Prud'homme, 2007; Hills and Squires, 2009; Lopez-Novoa and Nieto, 2009; Shariat et al., 2011). In veterinary medicine, elevated TGF- $\beta 1$ concentrations were found in dogs with liver fibrosis and lung fibrosis (Neumann et al., 2008; Krafft et al., 2011).

Aim of the underlying prospective study was measurement of TGF- $\beta 1$ in serum of diabetic dogs and its comparison with healthy controls and dogs with different fibrotic diseases. Further relation of TGF- $\beta 1$ and diabetic cataracts as one mayor complication of diabetes mellitus in dogs should be investigated. For that reason we measured expression of TGF- $\beta 1$ receptor in the epithelia of the anterior lens capsule.

\section{Animals}

Twenty healthy dogs were used as controls. All these dogs were clinical healthy and showed no abnormalities on clinical pathology, ultrasonography or radiology. These dogs were summarized as group 1. Group 2 consisted of 12 dogs with diabetes mellitus. Seven patients underwent surgery for removal of the lens material in a specialized veterinary clinic. Further diseases were excluded in this group, using clinical pathology and diagnostic imagine.

Finally, levels of TGF- $\beta 1$ were measured in 12 dogs with various fibrotic diseases. Six had liver fibrosis, three had kidney fibrosis and three had lung fibrosis. All diagnoses were confirmed by histopathology. 
These dogs were summarized as group 3. All procedures of this study conform to the German "Animal welfare law" and were carried out under the supervision of the Commissioner for "animal welfare", University of Goettingen.

\section{Sample collection}

For measurement of serum TGF- $\beta 1$ levels in dogs from all groups, blood was drawn from the cephalic vein. Blood samples were collected with a wide-gauge (20gauge) needle. To obtain serum, the blood was placed in a standard serum tube and was allowed to clot at room temperature for 30 minutes. After overnight incubation at $2-8^{\circ} \mathrm{C}$ the blood was centrifuged for 15 minutes at $1000 \mathrm{x} \mathrm{g}$. The supernatant was aliquoted and stored at $-80^{\circ} \mathrm{C}$ until further investigation. Samples of the anterior lens capsule were obtained during cataract surgery from the capsulorrhexis site.

\section{TGF-ק1 measurement}

Serum concentrations of TGF- $\beta 1$ were determined by use of a quantitative sandwich immunoassay (Quantikine Human TGF- $\beta 1$ ELISA; catalog number DB100B; R\&D Systems, Minneapolis, Minnesota, USA). According to the manufacturer's instructions, the test was previously tested and validated on canine blood, on the basis of a $94 \%$ identical amino acid sequence. The assay was performed according to the manufacturer's protocol. In brief, serum was activated by $1 \mathrm{~N} \mathrm{HCl}$, incubated at room temperature and neutralized by $1.2 \mathrm{~N} \mathrm{NaOH} / 0.5 \mathrm{M} \mathrm{HEPES}$. Prior to the assay, activated samples were diluted with calibrator diluent. Assay diluent was then applied to each well of the microplate, followed by either a standard for the standard curve, a control or the activated sample. After 2 hours' incubation at room temperature the plate was washed; TGF- $\beta 1$ conjugate was added and the plate incubated for another 2 hours. Following washing, protected from light the sample was applied to the wells and the plates incubated for 30 minutes. Finally, the visualization was stopped and the optical density was measured using a TECAN GENios Pro (TECAN Austria $\mathrm{GmbH}$, Groedig, Austria) at a wavelength of $450 \mathrm{~nm}$ and a wavelength correction of $570 \mathrm{~nm}$. Each measurement was carried out in triplicate and readings were averaged for the analyses. A standard curve was created for each measurement, based on the results for the diluted standards. The concentration of each probe was calculated according to the standard curve. Owing to the initial dilution of the probes prior to the assay, concentrations were multiplied by the final dilution factor.

\section{Immunohistochemistry}

Lens material was collected during surgery from all dogs with cataracts when anterior capsulorrhexis was performed. Samples of anterior lens capsule and associated lens epithelium were fixed in 5\% neutralbuffered formalin and processed for routine histology.
Immunhistochemistry was performed at the paraffinembedded tissue using the avidin-biotin-complex (ABC) method. As the primary antibody a polyclonal anti-TGF-beta receptor, type I (Millipore, Cat. ABF17) was established on canine placenta and inflamed skin and eye samples. Best results were seen with the Dako EnVison+ System-HRP (DAB), for use with rabbit primary antibodies.

\section{Statistics}

For statistical analysis we used the software R (Version 2.8, www.r-project.org). The age dependence of TGF$\beta 1$ was calculated using the Spearmans correlation test. The distributions of data were calculated using the Kolmogorov-Smirnov Test. To assess concentration differences between the diseased dogs and healthy controls, the Mann-Whitney U-Test was applied. Significance was defined at $\mathrm{p}<0.05$.

\section{Results and Discussion}

The control group was composed of eight male and 12 female dogs from different breeds; they were aged between five months and ten years.

The group of dogs with diabetes mellitus consisted of 12 dogs of different breeds aged between three and 12 years. Finally the dogs with confirmed organ fibrosis comprised seven male and five female dogs. These dogs were of different breeds and aged between six and 13 years.

All dogs in the study had measurable serum concentrations of TGF- $\beta 1$. The serum concentrations in the group of clinical healthy dogs (group 1) were between $30856 \mathrm{pg} / \mathrm{mL}$ and $40576 \mathrm{pg} / \mathrm{mL}$, with a median of $37585 \mathrm{pg} / \mathrm{mL}$. In the group of dogs with diabetes mellitus (group 2) serum concentrations of TGF- $\beta 1$ between 37240 and $106674 \mathrm{pg} / \mathrm{mL}$ could be measured, with a median of $61919 \mathrm{pg} / \mathrm{mL}$. Finally, the dogs with fibrosis in different organs (group 3) had TGF- $\beta 1$ concentrations between 32625 and 91178 $\mathrm{pg} / \mathrm{mL}$, with a median of $53634 \mathrm{pg} / \mathrm{mL}$.

There is no age dependence of TGF- $\beta 1$. Comparing all three groups, highly significant differences between the healthy controls and both other groups ( $p<0.001)$ could be found. The difference between group 2 (dogs with diabetes mellitus) and dogs with fibrotic diseases was not significant ( $\mathrm{p}>0.05$ ) (Fig. 1).

The expression of TGF- $\beta 1$ receptors in the anterior capsular epithelium was investigated in seven dogs. In four dogs no expression of TGF- $\beta 1$ receptors could be found on immunohistochemistry (Fig. 2). Three dogs expressed TGF- $\beta 1$ receptors with different intensity (Fig. 3). There was no correlation between the TGF- $\beta 1$ serum concentration and the expression of TGF- $\beta 1$ receptor on lens capsule.

In humans, elevated serum TGF- $\beta 1$ were found in diabetic patients (Jakuš et al., 2012; Mou et al., 2016). As far as we know no study about serum TGF- $\beta 1$ in diabetic dogs exist. 


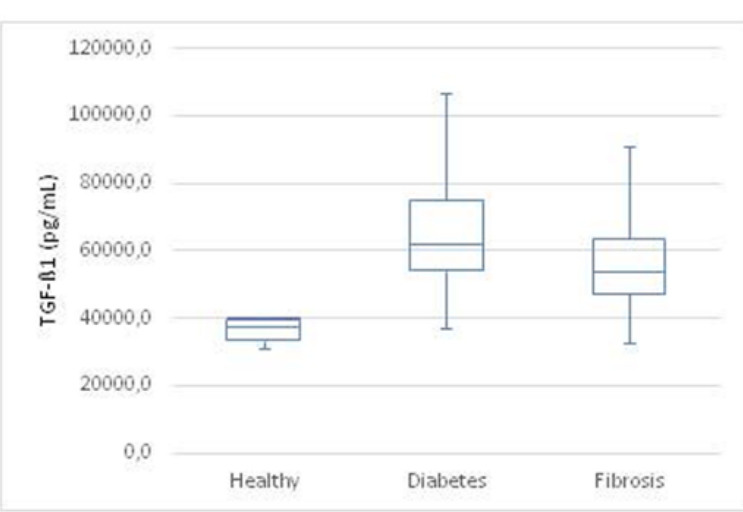

Fig. 1. Box-plot of TGF- $\beta 1$ serum concentrations in all investigated groups (Healthy controls; Diabetes mellitus; Fibrotic diseases).

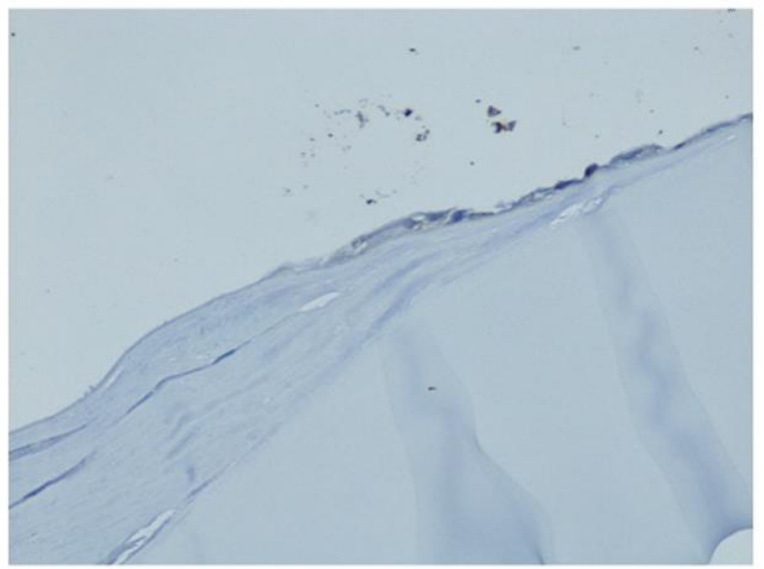

Fig. 2. No expression of the TGF- $\beta 1$ receptor in the lens capsule.

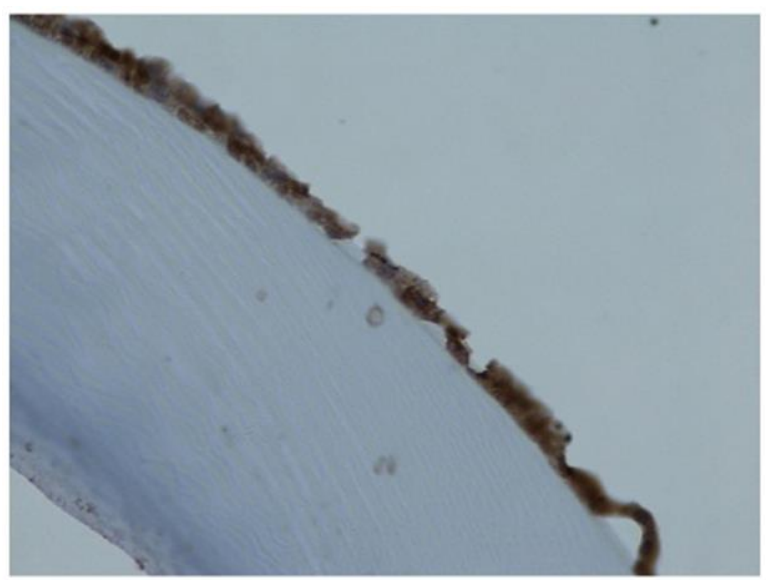

Fig. 3. Severe expression of the TGF- $\beta 1$ receptor in the lens capsule.

The results of our study show that TGF- $\beta 1$ serum concentrations in dogs with diabetes mellitus are comparable to those of dogs with fibrotic diseases and are significantly increased compared to healthy dogs. On that way we can confirm the results of human patients for dogs. Because elevation of serum TGF- $\beta 1$ is associated with fibrosis of different organs in dogs (Neumann et al., 2008; Krafft et al., 2011), we can assume that the elevation of serum TGF- $\beta 1$ in diabetic dogs also induces fibrosis. The mechanism about fibrosis in diabetic patients is probably induced by hyperglycemia. Different hypothesis exist how hyperglycemia induce fibrosis. For example via polyol pathway (Greene et al., 1987), via glycation of proteins (Brownlee et al., 1988) or via oxidative stress (Hunt et al., 1990). Further studies are necessary proofing the exact mechanism of fibrosis in diabetic dogs and its consequences.

In this study, we investigated secondly the association of TGF- $\beta 1$ with canine cataracts formation. Different publications in human medicine have assumed a role of TGF- $\beta 1$ in the pathogenesis of cataracts (DeIongh et al., 2001; Lovicu et al., 2002). For that purpose the expression of TGF- $\beta 1$ receptors in lens epithelial cells was measured. However, we could not identify the receptors in all cases. A possible explanation for this finding could be an inconsistent expression of the receptor on the cell membrane during the course of the disease. This has also been reported by other researchers (Roulot et al., 1999). Tissue fibrosis, as the final morphological step of organ rebuilding, is an inconsistent mechanism with periods of elevated collagen production and periods with lower production (McGee, 1977). Therefore, it is possible that TGF- $\beta 1$ receptor expression is also inconsistent, resulting in the absence of receptors in some cases.

In summary the results of this study show increased serum TGF- $\beta 1$ in diabetic dogs, which may can induce different complications associated with diabetes mellitus and may make dogs to a model for diabetes mellitus in humans.

\section{Conflict of interest}

The Authors declare that there are no conflict of interests.

Alevizopoulos, A. References Transforming growth factor-beta: the breaking open of a black box. Bioessays 19, 581-591.

Blobe, G.C., Schiemann, W.P. and Lodish, H.F. 2000. Role of transforming growth factor beta in human disease. N. Engl. J. Med. 342, 1350-1358.

Brownlee, M., Cerami, A. and Vlassara, H. 1988. Advanced glycosylation end products in tissue and the biochemical basis of diabetic complications. N. Engl. J. Med. 318(20), 1315-1321.

Colitz, C.M.H., Malarkey, D., Dykstra, M.J., McGahan, M.C. and Davidson, M.G. 2000. Histologic and immunohistochemical characterization of lens capsular plaques in dogs with cataracts. Am. J. Vet. Res. 61, 139-143. 
DeIongh, R., Gordon-Thomson, C., Chamberlain, C.G., Hales, A.M. and McAvoy, J.W. 2001. TGF $\beta$ Receptor Expression in Lens: Implications for Differentiation and Cataractogenesis. Exp. Eye Res. 72, 649-659.

Gangwani, R.A., Lian, J.X., Mc Ghee, S.M., Wong, D. and Li, K.K. 2016. Diabetic retinopathy screening: global and local perspective. Hong Kong Med. J. 22(5), 486-495.

Gardiner, T.A., Stitt, A.W., Anderson, H.R. and Archer, D.B. 1994. Selective loss of vascular smooth muscle cells in the retinal microcirculation of diabetic dogs. Br. J. Ophthalmol. 78(1), 54-60.

Gilbert, R.E. 2013. Endothelial loss and repair in the vascular complications of diabetes: pathogenetic mechanisms and therapeutic implications. Circ. J. 77(4), 849-856.

Greene, D.A., Lattimer, S.A. and Sima, A.A. 1987. Sorbitol, phosphoinositides, and sodiumpotassium-ATPase in the pathogenesis of diabetic complications. N. Engl. J. Med. 316(10), 599-606.

Hills, C.E. and Squires, P.E. 2009. TGF-beta1-induced epithelial-to-mesenchymal transition and therapeutic intervention in diabetic nephropathy. Am. J. Nephrol. 31, 68-74.

Hunt, J.V., Smith, C.C. and Wolff, S.P. 1990. Autoxidative glycosylation and possible involvement of peroxides and free radicals in LDL modification by glucose. Diabetes 39(11), 14201424.

Jakuš, V., Sapák, M. and Kostolanská, J. 2012. Circulating TGF- $\beta 1$, glycation, and oxidation in children with diabetes mellitus type 1. Exp. Diabetes Res. 2012: 510902. doi: 10.1155/2012/510902.

Juster-Switlyk, K. and Smith, A.G. 2016. Updates in diabetic peripheral neuropathy. F1000Res. doi: 10.12688/f1000research.7898.1.

Krafft, E., Heikkila, H.P. and Jespers, P. 2011. Serum and bronchoalveolar lavage fluid endothelin-1 concentrations as diagnostic biomarkers of canine idiopathic pulmonary fibrosis. J. Vet. Intern. Med. 25, 990-996.

Lawrence, D.A. 1996. Transforming growth factorbeta: a general review. Europ. Cytokine Network 7, 363-374.

Leung, W.K., Gao, L., Siu, P.M. and Lai, C.W. 2016. Diabetic nephropathy and endothelial dysfunction: Current and future therapies, and emerging of vascular imaging for preclinical renal-kinetic study. Life Sci. 166, 121-130.

Lopez-Novoa, J.M. and Nieto, M.A. 2009. Inflammation and EMT: an alliance towards organ fibrosis and cancer progression. EMBO Mol. Med. 1, 303-314.

Lovicu, F.J., Schulz, M.W., Hales, A.M., Vincent, L.N., Overbeek, P.A., Chamberlain, C.G. and McAvoy, J.W. 2002. TGF $\beta$ induces morphological and molecular changes similar to human anterior subcapsular cataract. Brit. J. Ophthalmol. 86, 220226.

McGee, J.D. 1977. Collagen deposition in liver disease. Annual Rheumat. Dis. 36, 29-36.

Mou, X., Zhou, D.Y., Zhou, D.Y., Ma, J.R., Liu, Y.H., Chen, H.P., Hu, Y.B., Shou, C.M., Chen, J.W., Liu, W.H. and Ma, G.L. 2016. Serum TGF- $\beta 1$ as a Biomarker for Type 2 Diabetic Nephropathy: A Meta-Analysis of Randomized Controlled Trials. PLoS One. 2016 Feb 22; 11(2):e0149513. doi: 10.1371/journal.pone.0149513.

Neumann, S., Kaup, F.J. and Beardi, B. 2008. Plasma concentration of transforming growth factor-beta1 and hepatic fibrosis in dogs. Can. J. Vet. Res. 72, 428-431.

Prud'homme, G.J. 2007. Pathobiology of transforming growth factor beta in cancer, fibrosis and immunologic disease, and therapeutic considerations. Lab. Invest. 87, 1077-1091.

Roulot, D., Sevcsik, A.M., Coste, T., Strosberg, A.D. and Marullo, S. 1999. Role of transforming growth factor $\beta$ type II receptor in hepatic fibrosis: Studies of human chronic hepatitis $\mathrm{C}$ and experimental fibrosis in rats. Hepatol. 29, 1730-1738.

Shariat, S.F., Semjonow, A., Lilja, H., Savage, C. and Vickers, A.J. 2011. Bjartell A. Tumor markers in prostate cancer I: blood-based markers. Acta Oncol. 50, 61-75.

Siperstein, M.D., Unger, R.H. and Madison, L.L. 1968. Studies of muscle capillary basement membranes in normal subjects diabetic, and prediabetic patients. J. Clin. Invest. 47, 1973-1999.

Sporn, M.B., Roberts, A.B., Born, G.V., Cuatrecasas, P. and Herken, H. 1990. Handbook of experimental pharmacology: Peptide growth factors and their receptors. Springer Berlin, New York.

Tsilibary, E.C. 2003. Microvascular basement membranes in diabetes mellitus. J. Pathol. 200, 537546. 